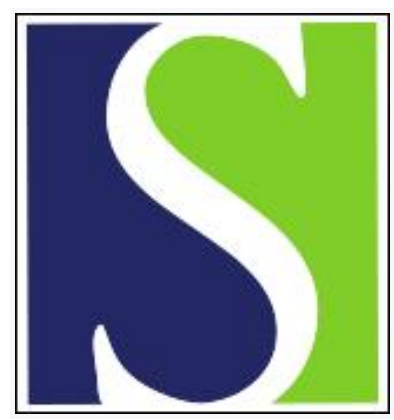

Scand J Work Environ Health 2003;29(5):363-377

https://doi.org/10.5271/sjweh.743

Issue date: Oct 2003

Excessive physical demands in modern worklife and characteristics of work and living conditions of persons at risk by Karlqvist LK, Härenstam A, Leijon O, Schéele P; MOA Research Group

Affiliation: National Institute for Working Lifem, SE-112 79 Stockholm, Sweden. lena.karlqvist@niwl.se

Refers to the following texts of the Journal: 1999;25(5):387-403 2000;26(1):7-19

The following articles refer to this text: 2007;33(6):401-404; 2010;36(5):357-365; 2010;36(6):466-472; 2019;45(3):267-279

Key terms: exposure assessment; gender; living conditions; metabolic level; modern worklife; paid work; physical demands; risk; unpaid work; work characteristic

This article in PubMed: www.ncbi.nlm.nih.gov/pubmed/14584517 


\title{
Excessive physical demands in modern worklife and characteristics of work and living conditions of persons at risk
}

\author{
by Lena K Karlqvist, PhD, ${ }^{1}$ Annika Härenstam, PhD, ${ }^{1}$ Oa Leijon, BSc, ${ }^{2}$ Patrik Schéele, BSc, ${ }^{2}$ the MOA \\ Research Group
}

\begin{abstract}
Karlqvist LK, Härenstam A, Leijon O, Schéele P, the MOA Research Group. Excessive physical demands in modern worklife and characteristics of work and living conditions of persons at risk. Scand J Work Environ Health 2003;29(5):363-377.

Objectives This study attempted to identify work and leisure-time conditions and life-style factors associated with excess metabolic levels (metabolic demands exceeding one-third of a person's aerobic capacity) at work among men and women.

Methods The study focused upon psychological, ergonomic, and physically loading factors and chemical and physical environmental conditions. Data were obtained through self-reports, interviews, workplace analyses, technical measurements, and observations. Gender-specific calculations were used in univariate analyses and in stepwise logistic regression models for excess metabolic level.

Results Twenty-seven percent of the men and twenty-two percent of the women worked at an excess metabolic level during their workday. Awkward work postures, heavy manual materials handling, high circulatory strain, chemical exposures, noise levels, much routine work, and many obstacles to job performance characterized their work conditions. The women had low skill discretion and more often atypical workhours, while the men showed high circulatory strain during leisure-time activities. Important negative life-style factors were a high consumption of alcohol for the men and a high body mass index and no or little regular physical exercise for the women. Conclusions Metabolic demands in worklife today remain high. The women who exceeded the recommended metabolic level at work in this study were characterized by low pay, poor health, and children at home, in addition to high physical load and psychosocial strain at work. These characteristics indicate a group with few possibilities to leave a hazardous job for a less physically demanding one. The men who worked at an excess metabolic level seemed to be characterized more by a life-style common in some male-dominated work cultures with monotonous work.
\end{abstract}

Key terms exposure assessment, gender, metabolic level, paid work, unpaid work.

During recent years, physical demands have been viewed in a wider perspective in which the total environment (both occupational and leisure-time conditions) has been considered. Earlier studies of both spheres have shown that both strain-inducing and supportive factors in the entire life situation are important for health (1$3)$. Thus the focus of our study is very broad - covering both private and work spheres.

A heavy physical load at work is a potential risk factor for many different diseases, such as those of the cardiovascular and musculoskeletal systems (4-6). Psychosocial job strain is often associated with musculoskeletal symptoms (7-11). Environments with high chemical and physical exposures are often found in combination with heavy physical workload, and an association with musculoskeletal symptoms is obvious (12-14).

The literature proposes an upper general tolerance limit for an 8-hour workday. It consists of mixed physical work, including handling operations, of one-third of a person's maximal capacity (15-19). A positive relationship between physical aerobic capacity and physical workload has been documented for young workers (20). In studies among middle-aged and elderly workers who have had physically strenuous jobs during their careers, a negative relationship has been observed between aerobic capacity and physical activities at work

$1 \quad$ National Institute for Working Life, Stockholm, Sweden.

2 Division of Occupational Medicine, Department of Public Health Sciences, Karolinska Institute, Stockholm, Sweden.

Reprint requests to: Dr Lena Karlqvist, National Institute for Working Life, SE-112 79 Stockholm, Sweden. [E-mail: lena.karlqvist@niwl.se] 
(21-24). In contrast to these findings, other studies have found a positive relationship between muscle strength and workload among elderly workers (20). The former findings support the hypotheses that long-term physically demanding work activities may have a deleterious effect on physical capacity, possibly in combination with aging. When these hypotheses are examined by comparing white- and blue-collar workers, differences in leisuretime physical activity, life-style factors, and health must be taken into account (25-26). Training effects can be attained within some weeks or months, but negative effects due to high strain and frequent overload over the years may take more time to develop (27-28).

An earlier study investigated the prevalence of excess metabolic level (metabolic work demands exceeding one-third of a person's aerobic capacity) among working men and women today and explored how externally assessed metabolic demands match physical function and capacity in jobs with the lowest and the highest demands (29). In summary, the calculation of individual metabolic demands during a "typical workday" showed that $27 \%$ of the men and $22 \%$ of the women worked at an excess metabolic level.

The aim of our present study was to compare those with and without an excess metabolic level in respect to work conditions, leisure-time activities and life-style factors. A second aim was to identify work and leisuretime conditions and life-style factors associated with an excess metabolic level at work among men and women.

This investigation had a cross-sectional design, and there has been no intention to identify exposure-response relationships (ie, to determine causes of excess metabolic level). However, it is important to identify situations in which such causal relations may occur and to consider a wide range of aspects-ergonomic, psychosocial, occupational hygienic, work and leisure-time conditions, and life-style factors.

\section{Participants and methods}

Our study was part of the interdisciplinary Swedish MOA study whose data were collected between 1995 and 1997. The full name of the MOA study is "Modern Work and Living Conditions for Women and Men: Development of Methods for Epidemiological Studies" (30).

\section{Selection process and description of the participants}

The MOA study strategically selected many different parts of worklife, including traditional workplaces and workplaces at which new forms of organization and production had been implemented, to be studied (30). The main principle for the selection of workplaces was to obtain a broad range of work conditions with optimal coverage in both the public and private sectors. The second aim was to achieve a distribution of important characteristics (ie, blue- and white-collar workers, selfemployed people, level of qualification and type of work object in occupation, ethnicity, age, and family situation) typical of the Swedish workforce during the same work period. The third principle was to achieve a gender-matched sample that included subgroups of men and women with different qualification levels and types of work and large enough to permit comparative statistical analyses.

Current statistics and research reports on labor-market and laborforce characteristics, as well as new classifications of branches and types of worksites (31), were used to help decide whether the subjects fit the criteria for selection and evaluation.

On the basis of such criteria, 101 male and $102 \mathrm{fe}-$ male workers were selected from the approximately 8000 employees in the selected 80 workplaces in 5 counties in Sweden. The selected sample covered 85 occupational titles with "people", "things", and "data" in roughly equal numbers, according to a modified classification system developed by Kohn \& Schooler (32). In the "people" category, the workers had an occupation in which they mainly worked with people, for example, nurse, dentist, teacher, cashier, and the like. In the "things" category, they mainly worked with objects, for example, construction worker, cleaner, cook. Finally, in the "data" category, data formed the main object of the workers' occupations, for example, journalist, secretary, computer operator, engineer. For each occupation and workplace, the gender representation was split as follows: percentage of women less than $30 \%$, $30-70 \%$, and more than $70 \%$. The workers were also classified according to whether they worked in private or public enterprises and by their socioeconomic group. They were split into the three age groups of under 31 years, 31-44 years, and over 44 years, as well as into three education categories, qualification levels, occupation, and wages (low, medium, and high). Civil status, such as single, cohabiting, with or without children, were also recorded (table 1), as well as demands at home. Seventy-five percent of the sample was matched pair-wise (man-woman) by type of work and qualification level of occupation. Whenever possible, the matched pairs were chosen at the same workplaces. The remaining $25 \%$ were chosen within gender-segregated workplaces and occupations. The men and women in the study group were, however, equally distributed regarding family situation, ethnicity, and qualification level, and they were similarly distributed regarding age and education level. 
Table 1. Demographic characteristic of the study group, representing cases and noncases, and the relative frequency of the men and women.

\begin{tabular}{|c|c|c|c|c|c|c|}
\hline \multirow[t]{2}{*}{ Characteristic } & \multicolumn{3}{|c|}{ Men } & \multicolumn{3}{|c|}{ Women } \\
\hline & $\begin{array}{c}\text { Cases } \\
(\mathrm{N}=25) \\
(\%)\end{array}$ & $\begin{array}{c}\text { Noncases } \\
(\mathrm{N}=69) \\
(\%)\end{array}$ & $\begin{array}{c}\text { Total } \\
\text { (N=101) } \\
(\%)\end{array}$ & $\begin{array}{c}\text { Noncases } \\
(\mathrm{N}=21) \\
(\%)\end{array}$ & $\begin{array}{c}\text { Cases } \\
(\mathrm{N}=73) \\
(\%)\end{array}$ & $\begin{array}{c}\text { Total } \\
(\mathrm{N}=102) \\
(\%)\end{array}$ \\
\hline \multicolumn{7}{|l|}{ Education level a } \\
\hline Low & 56 & 36 & 42 & $57^{b}$ & 34 & 38 \\
\hline Medium & 28 & 41 & 36 & 29 & 34 & 34 \\
\hline High & 16 & 23 & 22 & 14 & 32 & 28 \\
\hline \multicolumn{7}{|l|}{ Type of work } \\
\hline With people & 12 & 45 & 36 & 57 & 37 & 40 \\
\hline With things & $76^{b}$ & 26 & 39 & 43 & 19 & 26 \\
\hline With data & 12 & 29 & 25 & $\mathrm{Ob}^{\mathrm{b}}$ & 44 & 34 \\
\hline \multicolumn{7}{|l|}{ Women in the occupation } \\
\hline$<30 \%$ & $68^{b}$ & 39 & 46 & 14 & 22 & 24 \\
\hline $30-70 \%$ & 8 & 38 & 33 & 29 & 33 & 30 \\
\hline$>70 \%$ & 24 & 23 & 21 & 57 & 45 & 49 \\
\hline \multicolumn{7}{|l|}{ Employee category } \\
\hline Public sector & 20 & 26 & 25 & $52^{b}$ & 27 & 32 \\
\hline Public company & 12 & 12 & 12 & 0 & 7 & 5 \\
\hline Private sector & 68 & 62 & 63 & 48 & 66 & 63 \\
\hline \multicolumn{7}{|l|}{ Socioeconomic group } \\
\hline Blue-collar & $76^{b}$ & 42 & 48 & $90^{b}$ & 23 & 37 \\
\hline White-collar & 16 & 55 & 46 & 10 & 70 & 56 \\
\hline Self-employed & 8 & 3 & 6 & 0 & 7 & 7 \\
\hline \multicolumn{7}{|l|}{ Wages $^{c}$} \\
\hline Low & 24 & 17 & 20 & $71^{b}$ & 28 & 36 \\
\hline Medium & 52 & 46 & 46 & 24 & 53 & 45 \\
\hline High & 24 & 37 & 34 & 5 & 19 & 18 \\
\hline \multicolumn{7}{|l|}{ Givil status } \\
\hline Single with children & 0 & 4 & 4 & 10 & 8 & 8 \\
\hline Single without children & 24 & 26 & 25 & 24 & 19 & 19 \\
\hline Living with partner and children & 32 & 35 & 34 & 37 & 35 & 36 \\
\hline Living with partner but without children & 44 & 35 & 37 & 29 & 38 & 37 \\
\hline
\end{tabular}

a Years of education added to 9 years of compulsory school, low $=<2.5$ years, medium $=2.5-5.5$ years, high $=>5.5$ years.

${ }^{b}$ Significant difference between the cases and noncases $(P<0.05)$.

c Wages based on full-time workhours, including statutory gratuity after which the three groups were defined, low $=\mathrm{SEK}<14000 /$ month, medium $=\mathrm{S} E \mathrm{~K}$ $14000-20000 /$ month, high $=\mathrm{SEK}>20000 /$ month

The evaluation of the final sample showed that the MOA study group was similar to a randomly selected, large sample in most important aspects of demographic and background data at the individual level. The distribution of blue- and white-collar workers, self-employed people, occupations with regard to qualification level and work object, foreign background, parenthood, and marital status were almost the same as in the general working population during the chosen period. However, older persons were somewhat underrepresented and middle-aged people were overrepresented. The distribution of sectors, branches, and types of workplaces was found to be almost identical to that of the whole of Sweden during the same period.

The MOA sample deviated from the national situation regarding the distribution of women and men in female-dominated, male-dominated, and gender-mixed occupations. Gender-mixed occupations of men and women, men in female-dominated occupations, and women in male-dominated occupations were overrepresented (15-20\% difference in each group) as a result of the gender-matching sampling strategy. Consequently, when men and women were treated separately, there were differences with regard to type of work, labor-market characteristics, and work conditions when compared with randomly selected samples. However, for most of the questionnaire items on work conditions, the distribution of the responses on the total study group was strikingly similar to that in other large Swedish databases.

\section{Data collection}

The MOA study focused on psychologically loading factors, ergonomic and physically loading factors (ergonomic-physical exposure), and chemical and physical environmental conditions (chemical-physical exposure). It used self-reports, interviews, expert evaluations, job analyses, and technical measurements to collect the data. 
To begin with, the workers answered a public health questionnaire. Then they spent 1 day at the researchers' department of occupational health, where they answered several other questionnaires and participated in structured interviews and tests of their physical function and aerobic capacity. The data collection continued with field investigations, in which different quantitative and qualitative methods were used for several days for each subject during a 2-month period.

\section{Participants}

The ratio between the externally assessed [interviews, $33-35)$ ] physical activities of each person and his or her aerobic capacity showed that $25(27 \%)$ of the men and $21(22 \%)$ of the women were required to do work that exceeded their individual aerobic capacity (29).

Occupational category, socioeconomic group, and employee categories were described for the those with an excess metabolic level at work (cases) and those whose metabolic level at work did not exceed the recommended limits (noncases) (table 1).

Those with an excess metabolic level were mainly blue-collar workers, $76 \%$ of the men and $90 \%$ of the women. The men of this group were, for example, construction workers, house painters, truck drivers, and cleaners (ie, "thing" workers). Common occupations among the women of this group were nurse's aides, cooks, waitresses, and cleaners ("people" and "thing" workers). Most of the men in this group worked in maledominated occupations, while most of the women were found in female-dominated occupations. Both men with and without an excess metabolic level worked predominantly in the private sector. Most of the women in the "with" category worked in the private sector, while more women with than without a metabolic excess worked in the public sector.

The age distribution of the two groups was similar [mean 39 (SD 10.6) years for the men and 37 (SD 10.0) years for the women in the "with" group and mean 39 (SD 11.7) years for the men and 38 (SD 10.1) for the women in the "without" group]. More women in the with group than in the without group had a low level of education. Medium wages dominated among the men of both groups, while most of the women in the with group had low wages. Proportionally more women in the with group than in the without group lived with children.

An examination of the self-reported health status showed that more women in the with group than in the without group reported poorer general health, worse psychological well-being, and more eczema, musculoskeletal symptoms and skin symptoms. The women in the with group also reported more sleeping problems and had been on sick leave for musculoskeletal disorders to a higher extent than those in the without group. In addition more men in the with group than in the without group reported eczema and rated their general health status as worse, but they reported better psychological well-being (29).

\section{Assessment methods}

Interview. Exposures during leisure-time activities (frequency and duration), the duration of workhours (paid work in primary and extra jobs), hours used for commuting, hours doing home and household work and other compulsory tasks, and hours spent on own recreation, including hours for regular physical exercise, were obtained with the use of a task-oriented interview technique (33-35).

Technical measurements and observations. During the field investigations direct technical measurements were made, and systematic observations of ergonomic-physical workload were collected. The ergonomic-physical exposures of each person were recorded during one to two full workdays by four experienced ergonomists. Five different instruments were used to quantify the exposures, a heart rate recorder, a pedometer, a posimeter, an inclinometer, and systematic observation (36). During leisure-time activities, the heart rate recorder, pedometer, and posimeter were used before or after one to two full workdays to quantify ergonomic-physical exposure.

Expert assessment of chemical-physical exposures at the worksites and noise level measurements were made during one to two full workdays by four experienced occupational hygienists. The noise level was measured with the use of a Brüel \& Kjær noise meter with the microphone on the shoulder of the person being studied (37).

Job analysis. The aim of the job analysis was to describe each person's work from a psychosocial perspective, as objectively as possible, to supplement the person's own descriptions and experiences of his or her work. Four well-trained observers, who usually followed each person throughout one workday, conducted the job analyses. Each person's worktasks and their relative proportion of time constituted the work assignment. The level of qualification (eg, solving new problems or creativity, active use of occupational skills, and routine work or low mental demands), time-pressure, and timebound work were assessed as the percentage of the whole work assignment. Furthermore, possibilities to influence one's work conditions and obstacles to job performance were categorized into four levels. Further descriptions have been presented elsewhere (38-39). 
Self-reports. Ergonomic-physical exposure at work (eg, work postures, manual handling), psychosocial factors (such as demands, decision latitude, social support), chemical-physical exposure, and leisure-time activities were included and self-rated by all the participants who answered the public health questionnaire from the Stockholm County Council. Health and the life-style factors were all self-rated answers from the same questionnaire.

Data treatment and analysis. Gender-specific calculations were used. To calculate the statistically significant differences between the group with and that without an excess metabolic level at work with respect to work and leisure-time conditions and life-style factors, t-tests $(\mathrm{p}<0.05)$ were used for the continuous variables (including the index variables), whereas categorical variables were analyzed by chi-square tests.

The univariate analyses of work and leisure-time conditions and life-style factors were used as support for the selection of the variables used as determinants in the stepwise logistic regression models for the excess metabolic level (figure 1). However, the main principle was to select variables by hypotheses and to combine variables that reflect a broad variety of work and living conditions. When two variables were highly correlated, one was selected and one was excluded.

As a strong association was expected between aerobic demands, ergonomic-physical exposures, and excess metabolic level, only univariate analyses were performed for these exposures. These analyses had the objective of investigating in more detail the differrences in ergonomic-physical exposures between the groups with and without an excess metabolic level.

In the explanatory search process of the analyses intended to identify the variables associated with an excess metabolic level, four models of analyses with series of blocks of variables were performed. In the first model (i) psychosocial variables and (ii) chemical-physical variables were analyzed separately to identify work determinants in the second model. The next blocks were (iii) time distribution variables and (iv) leisure-time activities that identified time distribution and leisure-time activity determinants in a parallel second model. The third model was built from work determinants and time distribution and leisure-time activity determinants to create the main results. In order to investigate the impact of individually related factors, a block of (v) life-style factors was analyzed in parallel of the second model, and significant determinants were added in the fourth model, which created the final model. The independent variables appeared as dichotomized variables (work schedule, drinking high-alcohol beer and regular physical exercise), continuous variables based on technical measurements, and the duration of exposures (percentage of worktime), as well as ordinary scale variables such as sum indices of the questionnaire items and expert assessments of levels of exposure. The log-linearity was tested and considered satisfactory. The odds ratios were calculated as one unit increase in each of the variables.

On account of the aim of identifying the most important characteristics of those with metabolic levels in excess of recommended limits, backwards, stepwise logistic regressions were chosen. In the final model, age was adjusted to control for confounding. The point estimates of the odds ratio were stronger, but the confidence intervals were wider. Thus no adjustment for age was made since the distribution was similar for age in both groups.

\section{Results}

As the ergonomic-physical exposures were not included in the logistic regressions, the results of the univari-

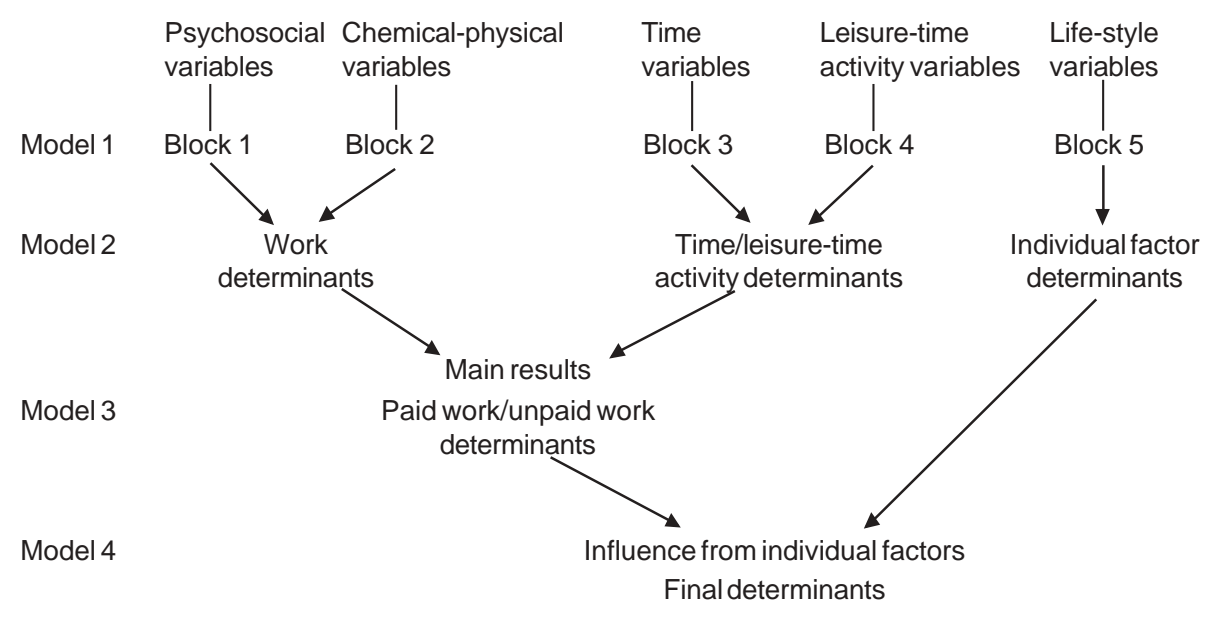

Figure 1. Step-wise logistic regression models for excess of metabolic level. 
ate analyses of these variables are presented more thoroughly (tables 2 and 3).

Male and female "cases" spent a significantly longer time in most of the awkward body postures, compared with the "noncases". The male and female cases spent an average of 3 and 5 hours more, respectively, of the total hours per week in loaded postures (standing with hands above shoulder level or below knee height or standing or sitting with hands far out from the body) than the noncases. The standing and walking postures differed an average of 12 hours per week among the men and 16 hours per week among the women, whereas the cases spent most hours in such postures (29).

The male and female cases spent a higher observed percentage of their worktime with manual handling than did the noncases. They also had higher circulatory strain, walked somewhat longer (not significant), and had fewer sitting worktasks than the noncases. The male cases also a spent longer time in deep trunk flexion $(>40$ degrees), and the female cases worked a longer time with their dominant arm elevated more than 60 degrees (an average of twice as much as the noncases) (table 2).

The male and female cases reported that they moved and exerted themselves physically to a greater extent than the noncases. In addition, they also reported higher perceived physical exertion at work (Borg scale 6-20). The frequency of lifts at work or outside work was higher for the male and female cases than for the noncases. The frequency of lifts above $20 \mathrm{~kg}$ was higher for both the men and women, while the frequency of lifts above $10 \mathrm{~kg}$ were higher only for the women (table 3 ).

Univariate analyses of all the other independent variables were made as support for choosing variables to be included in the regression analyses.

The results that follow are given according to the blocks of variables as introduced into the stepwise

Table 2. Ergonomic-physical exposures at work as measured by technical measurements among the cases (25 men and 21 women) and noncases (69 men and 73 women).

\begin{tabular}{|c|c|c|c|c|c|c|c|c|c|c|c|c|c|c|c|c|}
\hline \multirow[t]{3}{*}{ Gender } & & & \multicolumn{10}{|c|}{ Worktime (\%) } & \multirow{2}{*}{\multicolumn{2}{|c|}{$\begin{array}{l}\text { Walking } \\
\text { distance }^{d} \\
\text { (m/hour) }\end{array}$}} & \multirow{2}{*}{\multicolumn{2}{|c|}{$\begin{array}{c}\text { Heart-rate } \\
\text { range } \\
(\%)\end{array}$}} \\
\hline & \multicolumn{2}{|c|}{$\begin{array}{l}\text { Trunk } \\
\text { flexion }^{a} \\
\left(>20^{\circ}\right)\end{array}$} & \multicolumn{2}{|c|}{$\begin{array}{c}\text { Trunk } \\
\text { rotation a } \\
\left(>20^{\circ}\right)\end{array}$} & \multicolumn{2}{|c|}{$\begin{array}{l}\text { Manual } \\
\text { handling } \\
(>1 \mathrm{~kg})\end{array}$} & \multicolumn{2}{|c|}{$\begin{array}{l}\text { Trunk } \\
\text { flexion b } \\
\left(>40^{\circ}\right)\end{array}$} & \multicolumn{2}{|c|}{$\begin{array}{l}\text { Eevation } \\
\text { angle for } \\
\text { dominant } \\
\operatorname{arm}^{\mathrm{b}}\left(>60^{\circ}\right)\end{array}$} & \multicolumn{2}{|c|}{ Sitting $^{c}$} & & & & \\
\hline & Mean & $\mathrm{SD}$ & Mean & SD & Mean & $\mathrm{SD}$ & Mean & $\mathrm{SD}$ & Mean & $\mathrm{SD}$ & Mean & SD & Mean & $\mathrm{SD}$ & Mean & SD \\
\hline \multicolumn{17}{|l|}{ Men } \\
\hline Cases & 13 & 8 & 9 & 17 & 11 & $16^{f}$ & 11 & $6^{f}$ & 6 & 4 & 38 & $20^{f}$ & 589 & 407 & 30 & $9^{f}$ \\
\hline Noncases & 15 & 14 & 6 & 10 & 4 & 7 & 7 & 5 & 5 & 6 & 49 & 23 & 472 & 263 & 20 & 7 \\
\hline \multicolumn{17}{|l|}{ Women } \\
\hline Cases & 15 & 11 & 8 & 15 & 5 & $5^{f}$ & 10 & 8 & 6 & $4^{f}$ & 24 & $16^{f}$ & 397 & 195 & 22 & 6 \\
\hline Noncases & 16 & 16 & 6 & 8 & 2 & 4 & 9 & 8 & 3 & 3 & 53 & 24 & 312 & 205 & 17 & 6 \\
\hline
\end{tabular}

a Portable ergonomic observation method.

b Inclinometer.

c Posimeter.

d Pedometer.

e Heart-rate recorder.

f Significant differences between the cases and noncases $(P<0.05)$.

Table 3. Ergonomic-physical exposures at work as measured by the questionnaire method among the cases (25 men and 21 women) and noncases (69 men and 73 women).

\begin{tabular}{|c|c|c|c|c|c|c|c|c|}
\hline \multirow[t]{3}{*}{ Gender } & \multicolumn{8}{|c|}{ Worktime (\%) } \\
\hline & \multicolumn{2}{|c|}{ Physical exertion ${ }^{a}$} & \multicolumn{2}{|c|}{ Move and exert oneself } & \multicolumn{2}{|c|}{ Frequency of lifts $>20 \mathrm{~kg}$} & \multicolumn{2}{|c|}{ Frequency of lifts $>10 \mathrm{~kg}$} \\
\hline & Mean & SD & $\begin{array}{l}\text { Sitting still and } \\
\text { easy, some } \\
\text { movement }\end{array}$ & $\begin{array}{l}\text { Moderate heavy } \\
\text { and heavy }\end{array}$ & $\geq 11 /$ day & $<11 /$ day & $\geq 11 /$ day & $<11 /$ day \\
\hline \multicolumn{9}{|l|}{ Men } \\
\hline Cases & 14 & $3^{b}$ & 36 & $64^{b}$ & $40^{b}$ & 60 & 40 & 60 \\
\hline Noncases & 12 & 3 & 64 & 33 & 13 & 87 & 21 & 79 \\
\hline \multicolumn{9}{|l|}{ Women } \\
\hline Cases & 15 & $2^{b}$ & 24 & $76^{b}$ & $29^{b}$ & 71 & $43^{b}$ & 57 \\
\hline Noncases & 12 & 3 & 66 & 34 & 0 & 100 & 10 & 90 \\
\hline
\end{tabular}

a Rating of perceived exertion 6-20.

b Significant differences between the cases and the noncases $(P<0.05)$. 
logistic regression analysis. The results are presented in the appendices.

\section{Psychosocial exposures, block 1}

Work for both the male and female cases was characterized by more routine job tasks than for the noncases. The female cases also had less creative work, less influence on the work situation, and more obstacles to job performance than the noncases. For them work was characterized by a greater amount of time-bound work, while male cases showed less time-bound work than the noncases (appendix 1). The male and female cases reported less skill discretion at work than the noncases did (appendix 1).

\section{Chemical-physical exposures, block 2}

The experts classified the male and female cases into work in environments with higher chemical-physical exposures than the noncases (appendix 2). Both the male and female cases worked in environments with higher measured noise levels than the noncases (appendix 2). Chemical-physical exposures collected from the self-administrated questionnaires showed higher exposure levels for both the male and female cases than for the noncases (appendix 2).

\section{Workhours, block 3}

The male cases spent more hours commuting than the noncases, and more female cases had atypical workhours than the female noncases (appendix 3).

\section{Activities outside paid work, block 4}

For activities outside paid work, only circulatory strain differed significantly between the male cases and noncases. The male cases had higher circulatory strain. No significant differences were found among the women (appendix 4).

\section{Life-style factors, block 5}

More male cases drank high-alcohol beer (above average) at least once a week and were heavy drinkers sometimes during the week than the noncases. Among the women, the situation was the opposite. The mean body mass index (BMI) was higher among the female cases than among the noncases, but a higher proportion of male cases than noncases was classified as "overweight" when defined according to the World Health Organization. Little regular physical activity $(<120$ minutes/ week) or no regular physical activity at all was found for $44 \%$ and $62 \%$ of the male and female cases, respectively, compared with $36 \%$ and $23 \%$ of the noncases (appendix 5).

\section{Stepwise logistic regression analyses}

The results of the logistic regression analyses of the association of work conditions, leisure-time activities, and life-style factors with an excess metabolic level are presented in table 4.

The significant psychosocial variables at work in the first model (block 1) were, for both the women and the men, a higher percentage with routine work and more obstacles to job performance. However, the male cases had less time-bound work than the other men, while the female cases had more time-bound work than the noncase women. The women who exceeded their recommended metabolic level also reported lower skill discretion than the other women.

The only significant chemical-physical exposures at work (block 2) were more chemical exposures for the male cases and a higher noise level for the female cases.

The second model included all work determinants (blocks 1 and 2). Its analysis showed that chemicalphysical exposures were no longer significant. However, routine work and obstacles to job performance remained significant for both the men and the women. For the male cases, little time-bound work remained significant, and, for the female cases, low skill discretion remained significant.

Time distribution and exposures during leisure-time activities (block 3 and 4) were analyzed in the next step. For the men, high circulatory strain and, for the women, an atypical work schedule were significantly associated with an excess metabolic level.

The main results are shown in the third model, in which the work determinants, time distribution variables, and exposures during leisure-time activities were analyzed. Still, routine work and obstacles to job performance were significantly associated with an excess metabolic level for both the men and the women. In addition low skill discretion for the women and high circulatory strain during leisure-time activities for the men were significant determinants.

When life-style factors were included (block 5), a high consumption of high-alcohol beer was significant for the men, and a high body mass index and little regular physical exercise were significant for the women.

When the work determinants, the time and leisuretime activity determinants, and life-style factors were analyzed together (model 4), only routine work and high circulatory strain during leisure-time activities showed a significant association with an excess metabolic level for the men. In the analyses of the women, low skill discretion, many obstacles to job performance, atypical 
Table 4. Gender-specific stepwise logistic-regression models for excess metabolic level. The odds ratios have been calculated for a onestep increase. (See the text.) ( $M=$ men, $W=$ women, $O R=$ odds ratio, 95\% Cl=95\% confidence interval)

\begin{tabular}{|c|c|c|c|c|c|c|c|c|c|c|c|c|c|c|c|c|c|}
\hline \multirow{2}{*}{\multicolumn{2}{|c|}{ Range }} & \multicolumn{4}{|c|}{ Model $1^{\text {a }}$} & \multicolumn{4}{|c|}{ Model $2^{b}$} & \multicolumn{4}{|c|}{ Model $3^{c}$} & \multicolumn{4}{|c|}{ Model $4^{d}$} \\
\hline & & & M & & W & & M & & W & & M & & W & & M & & W \\
\hline$M$ & W & OR & $95 \% \mathrm{Cl}$ & OR & $95 \% \mathrm{Cl}$ & OR & $95 \% \mathrm{Cl}$ & OR & $95 \% \mathrm{Cl}$ & OR & $95 \% \mathrm{Cl}$ & OR & $95 \% \mathrm{Cl}$ & OR & $95 \% \mathrm{Cl}$ & OR & $95 \% \mathrm{Cl}$ \\
\hline
\end{tabular}

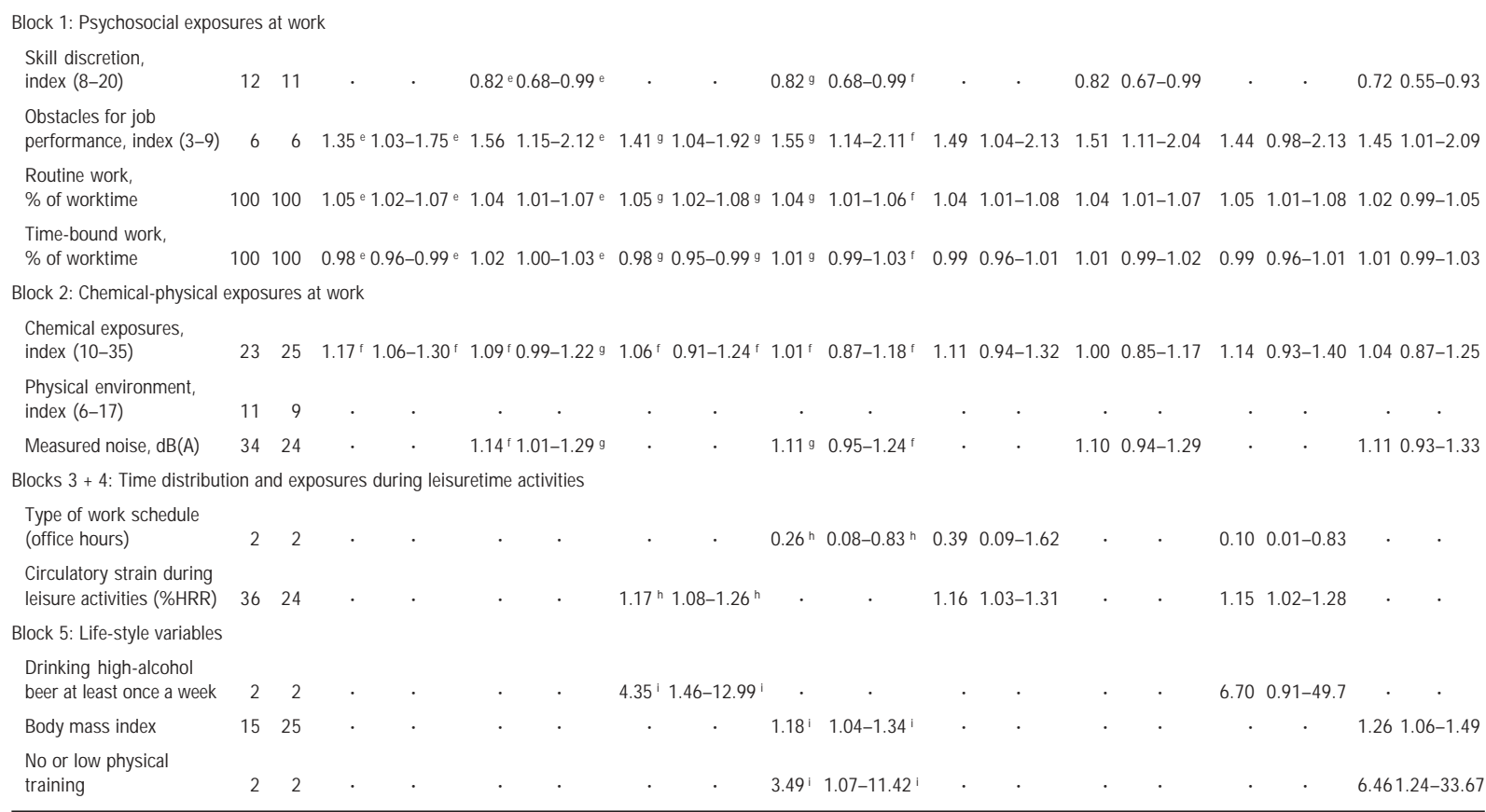

a Models $1 \mathrm{a}$ and $1 \mathrm{~b}$ include the variables in blocks 1 and 2 , respectively. (See the marked variables in the appendix.)

${ }^{b}$ Models $2 \mathrm{a}$ and $2 \mathrm{~b}$ include the variables in blocks $1+2$ and the variables in blocks $3+4$ and 5 , respectively. (See the marked variables in the appendix.)

c Model 3 includes the variables in blocks $1+2+3+4$.

d Model 4 includes the variables in model 3 , as well as the variables in block 5 , significant in model $2 \mathrm{~b}$.

e Model 1a

' Model 2.

9 Model $1 \mathrm{~b}$.

h Model 2a.

i Model 2b.

workhours, a high body mass index, and little regular physical exercise were significant variables.

\section{Discussion}

\section{Work conditions}

Most of the "cases" in this study were associated with occupations known for their physically strenuous worktasks. Both the men and the women who exceeded their recommended metabolic level were exposed to ergonomic risk factors at work, such as awkward work postures, manual handling, and high circulatory strain. These results were expected, but it was revealing to get detailed information on the differences in work postures and the different distribution between the men and women. For example, female cases spent four more hours a week in a standing posture working with their hands far out from the body than the female noncases, while, among the men, no differences between the cases and noncases were found. By using self-reports and interviews, we could show both metric qualities and distributions of means for cases and noncases and could compare data collected with the different methods (intermethod reliability) (40).

Adverse psychosocial exposures at work were more common among the women than among the men. The female cases had more irregular workhours, more routine work, less creative work, more obstacles to job performance, more time-bound work, less influence on the work situation, and less skill discretion than the remaining group of women. This finding agrees with the results of other studies showing a strong covariation between adverse psychosocial work conditions and high physical workload among women but not among men (8). It has been proposed that such gender differences may be due to the fact that women tend to remain in monotonous, physically straining jobs more often than men instead of moving to higher and less physically 
straining positions (2). The male cases also had less skill discretion and more routine work, but less time-bound work than the male noncases. Both the men and the women who exceeded their recommended metabolic level worked in environments with high chemical-physical exposures and high noise levels. Thus those who exceeded their recommended metabolic level seemed to be an "exposed" group in most aspects.

In this cross-sectional study of work and leisure-time activities, an unexpected high percentage was found of both men and women with jobs in which the work required a metabolic level that exceeded the recommended level. Few general population studies have been carried out in which the externally assessed physical activity of each individual's work has been related to his or her own measured aerobic capacity. Many studies have focused specific occupations, for example, construction workers, home care workers, airline hostesses, welders, furniture removers, and the like $(36,41-43)$. Such occupations are known to be physically strenuous in the traditional sense of the word. The work of airline hostesses, as an example, entails a great deal of walking and a work pace that is constrained to a considerable degree. Food serving and other duties must be performed within a given period of time, and hostesses have limited opportunities for determining their work rate. One study of a small group of hostesses found a significant correlation between median heart rate during work and maximal oxygen uptake expressed in milliliters of oxygen per kilogram of body weight. The results showed that the lower the work capacity, the higher the heart rate (44). When workers are unable to choose their own work pace, the relative workload varies inversely with work capacity. Signs of work-related problems in the form of fatigue, aching legs, and the like were especially pronounced among people with low work capacities. Today, industrial occupations and the number of industrial workers with physically strenuous worktasks in this traditional sense of the word have decreased (45). Several studies have, instead, shown that a lack of security and job decision latitude in combination with high demand levels increases the risk of ill health (46-47). For many enterprises and public authorities the need for flexibility and leaner organizations has resulted in a search for employees with higher qualifications who could, without any lengthy period of learning or introduction, take on a greater number of more complicated tasks. This type of action has also put more pressure on many employees (47). Physically strenuous worktasks have also partly been replaced by "light", repetitive, monotonous worktasks performed in a sitting position (48). The number of heavy worktasks, particularly in the service sector, and often in combination with time pressure and job strain, has increased and heavy worktasks in health care are still a reality
$(45,47)$. The individual's capacity for strenuous work remains important with respect to successful work performance. When the work rate is constrained, the relative strain of the individual varies inversely with physical work capacity. In addition, other risk factors have increased, for example, static muscular work, repetitive movements, time pressure, lack of pauses, lack of recovery $(46,48)$. This increase may be a result of a new work organization with increased work intensity and a down-sized work force that has to do more tasks and is lacking important rest breaks and recovery time (49).

\section{Leisure-time activities}

Those who exceeded their recommended metabolic level during paid work were not exposed during leisure-time activities to increased levels of strain when they were compared with the male and female noncases. However, one exception was found among the men who exceeded their recommended metabolic level—they had higher measured circulatory strain during leisure-time activities during a workday than the remaining group of men did. This finding could not be explained by more regular exercise (physical training activities), reported extra jobs, or domestic work since they showed less time spent on these activities than the remaining group of men. One reason could be that they had additional worktasks, which they did not report, that also gave high circulatory strain. The exposures during leisure-time activities did not differ between the female cases and female noncases, but the exposures during paid work did.

\section{Life-style}

Physical fitness was poor among both the men and the women, and this lack may reflect the situation of the general population (28). Physical demands in worklife of today are still high, a fact that was reflected in a mismatch between the individual's physical capacity and the physical demands of the work for $25 \%$ of the population. In other words, there is a need to be fit enough to be able to take a physically demanding job and stay in it. The job in itself will not allow for a training effect (17-18). One needs extra energy resources to avoid tearing oneself down during employment. The workload does not have training effects on individual physical work capacity similar to those of aerobic exercise (50).

\section{Persons at risk}

This study was part of an interdisciplinary research project and had the advantage of using a comprehensive perspective of work exposures (ergonomic-physical, psychosocial, and chemical-physical), as well as 
exposures during leisure-time activities and life-style factors. Through this comprehensive data collection, it was possible to explore risk factors, in a broad perspective, for metabolic levels in excess of the recommended level. Many risk factors of different kinds accumulated among persons who exceeded their recommended metabolic level. Different patterns emerged for the men and women. The male cases showed no decreased health status when compared with the remaining group of men. They may have included a selection of men healthy enough to be involved also in extra jobs. But it is reasonable to ask what will happen in the long run with the group of men who had an extremely low physical capacity and unhealthy life-style behavior.

The female cases had workloads that were extremely high. During leisure-time activities, the workload did not differ from the remaining group of women. However, accumulated hazardous exposures in paid work may be enough to cause ill health (2-3). The women who exceeded their recommended metabolic level during paid work showed a poor health status when compared with the remaining group of women. It could not be excluded that "double" burden plays a role for women. On the basis of the cross-sectional data, it is difficult to conclude whether these women have had earlier exposures from unpaid work. As many of them now have reduced health, as well as a low income, they may manage because of a lower unpaid workload. It may not be possible for them to avoid a high workload in paid work for economic reasons.

The work exposures were strongly related to an excess metabolic level, and this finding was more evident for the women. For the men, life-style factors also played an important role.

The results presented were based on data of high quality, obtained by a combination of field measurements, interviews, and questionnaires collected within a two-month period for each person.

\section{Methodological considerations}

The relatively small study group, and also the crosssectional design of the MOA study, naturally limits the possibility of analyzing causal relationships. However, in order to prevent ill health in relation to excessive physical demands, it would be valuable to identify characteristic work and living conditions for those at risk.

The MOA study comprised many different parts of worklife, both traditional workplaces and workplaces at which new forms of organization and production had been introduced. They were strategically selected (ie, with the support of current statistics and reports on different branches of the Swedish labor market and of conditions of different occupations). The study group has many similarities with randomly selected samples; hence the results from our study should be valid for generalizations (49) (table 1). Thus the prevalence of an excess metabolic level for $22 \%$ of the women and $27 \%$ of the men is probably a realistic prevalence rate for the Swedish working population. Excess metabolic levels have mainly been studied in specific, physically demanding jobs. Consequently, information on the prevalence in the general working population has been unknown. Still, it has often been suggested that the physical demands of worklife have decreased considerably during the last several decades $(45,47)$.

Step-wise models of logistic regression will, in the end, show the strongest determinants of an excess metabolic level. Only variables that were not highly correlated were included in the analyses. Consequently, the final results should indicate work and living conditions that are most often found among persons who have a metabolic level at work in excess of the recommended level.

The odds ratios in the stepwise models of the logistic regression showed low numbers, although significant (95\% confidence intervals above or below 1.00). One reason for this result could be that the odds were calculated for a one-step increase. Three determinants were dichotomized, work schedule, drinking high-alcohol beer and absence of physical training, while other scales were ranges $(0-100,8-20$, or 20-35). Therefore, no or little regular physical exercise (women) had an odds ratio of 6.46 , while routine work with a range between 0 and 100 had an odds ratio of 1.05 (men). In other words, in order to evaluate the importance of the size of the odds ratios, the range has to be taken into account.

\section{Implications}

The possibility that the subjects had selected or avoided certain kinds of jobs on the basis of physical capacity cannot be ruled out. Health selection both into and out of jobs with high physical loads is well known. For example, young men in physically demanding jobs have been found to be stronger than other men (suggesting a preferential selection into heavy jobs) (23), and women with health problems working in physically demanding jobs have been found to change jobs more often than other women (51). However, changing from physically demanding and low-skill jobs is much harder today because of the current trends of the labor market.

Empowerment strategies for avoiding metabolic levels in excess of recommended levels could be of the following different kinds:

- Physical exercise would undoubtedly be of great value, both for the individual (keeping healthy) and for society (keeping the work force in production and 
avoiding increased costs from absenteeism). There is growing concern today about the low general fitness of the general population-especially among many children - and some special programs have been started to promote higher fitness levels, health and quality of life [eg, the Bunkeflo project (see http:// bli.fysisktaktiv.nu/)].

- Particularly in jobs with high workload, overall physical fitness is essential; therefore, physical training during vocational education would be of value.

- Furthermore, adapting jobs with physical workloads that are too high to the physical capacity of the work force is important. Such adaptation calls for technical or organizational changes.

- Similarly, work organizations in which enough breaks, recovery, and relaxation periods are a natural component should be encouraged.

- Learning and development possibilities at work are likely to both increase skill discretion and facilitate a change to less physically demanding jobs.

- Finally, improving life-style behavior would be particularly important for men with high physical strain.

\section{Concluding remarks}

The results of our study indicate that aerobic demands and exposures in worklife of today remain high. These high demands and exposures are reflected in a mismatch between workers' physical capacities and the physical demands of work. This statement holds for a quarter of the population. Work exposures were strongly related to an excess of recommended metabolic levels, particularly among women. There seem to be large gender differences with regard to the characteristics of women and men who work at excess metabolic levels. Low-paid women with poor health and living with children at home, in addition to having a high physical load and psychosocial strain at work, have few possibilities to leave a hazardous job for a less physically demanding one. Men who work at excess metabolic levels seem to be characterized more by a life-style common in some male-dominated work cultures and by monotonous work.

\section{References}

1. Barnett R, Marschall N. The relationship between women's work and family roles and their subjective well- being and psychological distress. In: Frankenheauser M, Lundberg U, Chesney M, editors. Women, work and health: stress and opportunities. New York (NY): Plenum Press; 1991.

2. Lundberg U. Influence of paid and unpaid work on psycho- physiological stress responses of men and women. J Occup Health Psychol 1996;2:117-30.

3. Pugliesi K. Work and well-being: gender differences in the psychological consequences of employment. J Health Soc Behav 1995;36:57-71.

4. Hagberg M. Exposure variables in ergonomic epidemiology. Am J Ind Med 1992;21:91-100.

5. Winkel J, Westgaard R. Occupational and individual risk factors for shoulder-neck complaints. Part II. The scientific basis for the guide [review]. Int J Ind Ergon 1992;10:85-104.

6. Hallqvist J, Moller J, Ahlbom A, Diderichsen F, Reuterwall C, de Faire U. Does heavy physical exertion trigger myocardial infarction? A case-crossover analysis nested in a populationbased case-referent study. Am J Epidemiol 2000;151(5):45967.

7. Bongers PM, de Winter CR, Kompier MAJ, Hildebrandt VH. Psychosocial factors at work and musculoskeletal disease. Scand J Work Environ Health 1993;19:297-312.

8. Josephson M, Gustafsson H, Ahlberg-Hultén G, Härenstam A, Theorell T, Wiktorin C, et al. Differences in the association between psychosocial work conditions and physical work load in female- and male-dominated occupations. Am Ind Hyg Assoc J 1999;60:673-78.

9. Hoogendoorn WE, van Poppel MNM, Bongers PM, Koes BW, Bouter LM. Physical load during work and leisure time as risk factors for back pain [review]. Scand J Work Environ Health 1999;25(5):387-403.

10. Devereux J, Buckle P. The risk of neck, shoulder and upperlimb musculoskeletal disorders due to interactions between physical and psychosocial work risk factors. In: Program and abstract book, International Ergonomics Association XIVth Triennial Congress and Human Factors and Ergonomics Society 44th Annual Meeting; July 29-August 4. San Diego, California USA, 2000.

11. Ariëns GAM, van Mechelen W, Bongers PM, Bouter LM, van der Wal G. Physical risk factors for neck pain [review]. Scand J Work Environ Health 2000;26:7-19.

12. Hagberg M, Silverstein B, Wells R, Smith M, Hendrick H, Carayon P, et al. Chapter 6. In: Kuorinka I, Forcier L, editors. Work related musculoskeletal disorders (WMSDs): a reference book for prevention. London: Taylor \& Francis; 1995. p 247-70.

13. Kjellberg A. Subjective, behavioral and psychophysiological effects of noise. Scand J Work Environ Health 1990;16 Suppl 1:29-38.

14. Kjellberg A, Sköldström B, Tesaiz M. Equal EMG response levels to a 100 and $1000 \mathrm{~Hz}$ tone. In: Lawrence A., editor. Proceedings of Internoise Sydney: Australian Acoustical Society; 1991:847-50.

15. Jørgensen K. Permissible loads based on energy expenditure measurements. Ergonomics 1985;28:365-69.

16. Grandjean E. Fitting the task to the man:n a textbook of occupational ergonomics. 4th ed. London: Taylor \& Francis; 1988. p 92-99.

17. Ilmarinen J. Job design for the aged with regard to decline in their maximal aerobic capacity, part 1: guidelines for the practitioner. Int J Ind Ergon 1992;10:53-63.

18. Ilmarinen J. Job design for the aged with regard to decline in their maximal aerobic capacity, part 2: the scientific basis for the guide. Int J Ind Ergon 1992b;10:65-77.

19. Wigæus Hjelm E, Winkel J, Nygård CH, Wiktorin C, Karlqvist L, Stockholm MUSIC I Study Group. Can cardiovascular load in ergonomic epidemiology be estimated by selfreport? J Occup Environ Med 1995;10:1210-17. 
20. Schibye B, Hansen AF, Søgaard K, Christensen H. Aerobic power and muscle strength among young and elderly workers with and without demanding work tasks. Appl Ergon 2001;32:425-31.

21. Nygård C-H, Luopajärvi T, Cedercreutz G, Ilmarinen J. Musculoskeletal capacity of emoloyees aged 44 to 58 years in physical, mental and mixed types of work. Eur J Appl Physiol 1987;56:555-61.

22. Nygård C-H, Loupajärvi T, Suurnäkki T, Ilmarinen J. Muscle strength and muscle endurance of middle-aged women and men associated to type, duration and and intensity of muscular load at work. Int Arch Occup Environ Health 1988;60:29197.

23. Era P. Determinants of isometric muscle strength in men of different ages. Eur J Appl Physiol 1992;64:84-91.

24. Miettinen M, Louhevaara V. Job demands, physical fitness, work ability, and age of vehicle inspectors. Int J Ind Ergon 1994;13:337-42.

25. Ford ES, Merritt RK, Heath GW, Powell KE Washburn RA, Kriska A, et al. Physical activity behaviors in lower and higher socioeconomic populations. Am J Epidemiol 1991;133(12): 1246-56.

26. Rantanen T, Parkatti T, Heikkinen E. Muscle strength according to level of physical exercise and educational background in middle-aged women in Finland. Eur J Appl Physiol 1992;65:507-12.

27. De Zwart B, Frings-Dresen M, Van Dijk F. Physical workload and the aging worker: a review of the literature. Int Arch Occup Environ Health 1995;68:1-12.

28. Torgén M, Punnett L, Alfredsson L, Kilbom Å. Physical capacity in relation to present and past physical load at work: a study o 484 men and women aged 41 to 58 years. Am J Ind Med 1999;36:388-400.

29. Karlqvist L, Leijon O, Härenstam A, the MOA Research Group. Physical demands in working life and individual physical capacity. Eur J Appl Physiol. In press.

30. Härenstam A, Bodin G, Karlqvist L, Nise G, Schéele P. The modern work-style: assessing exposures in future jobs. In: Hagberg M, Knave B, Lillienberg L, Westberg H, editors. X2001—exposure assessment in epidemiology and practice. Stockholm: National Institute for Working Life; 2001. Arbete och Hälsa 2001;10:3-5.

31. Giertz E. Measuring success: identifying performance indicators. Malmö: Celemilab International AB; 2000.

32. Kohn ML, Schooler C. Work and personality: an inquiry into the impact of social stratification. Norwood (NJ): Ablex; 1983.

33. Wiktorin C, Selin K, Ekenvall L, Alfredsson L, MUSICNorrtälje Study Group. An interview technique for recording work postures in epidemiological studies. Int J Epidemiol 1996;25:171-79.

34. Montoye H, Kemper H, Saris W, Washburn R. Chapter 2. In: Fowler M, Basic M, editor. Measuring physical activity and energy expenditure. Champaign (IL), Human Kinetics; 1996. p 6-14.

35. Pernold G, Wigaeus Tornqvist E, Wiktorin C, Mortimer M, Karlsson E, Kilbom $\AA$, et al. Validity of occupational energy expenditure assessed by interview. Am Ind Hyg Assoc J
2002;63:29-33

36. Karlqvist L, Winkel J, Wiktorin C, Stockholm MUSIC I Study Group. Direct measurements and systematic observations of physical workload among medical secretaries, furniture removers and male and female reference populations. Appl Ergon 1994;25(5):319-26.

37. Nise G, Andersson L, Borg K, Lewné M, Borg K, Härenstam A. Workers ability to estimate noise exposure in the MOAstudy [abstract-37]. In: 4th International Scientific Conference of the International Occupational Hygiene Association, 14-20 July 2000, Cairns Australia. Derby: International Occupational Hygiene Association; 2000. p 37.

38. Waldenström M, Josephson M, Person C, Theorell T. Interview reliability for assessing mental work demands. J Occup Health Psychol 1998;3(3):209-16.

39. Waldenström K, Lundberg I, Waldenström M, Härenstam A, the MOA Research Group. Does psychological distress influence reporting of demands and control in work? Occup Environ Med. In press.

40. Leijon O, Wiktorin C, Härenstam A, Karlqvist L, the MOA Research Group. Validity of a self-administered questionnaire for assessment of physical work loads in a general population. J Occup Environ Med 2002;44(8):724-35.

41. Åstrand I. Physical demands in worklife. Scand J Work Environ Health 1988;14 Suppl 1:10-3.

42. Lusa S, Louhevaara V, Kinnunen K. Are the job demands on physical work capacity equal for young and aging fire fighters? J Occup Med 1994;36:70-74.

43. Torgén M, Nygård C-H, Kilbom Å. Physical workload, physical capacity and strain among elderly female aides in homecare service. Eur J Appl Physiol 1995;71:444-52.

44. Åstrand I. Arbeitsphysiologie [Work physiology]. New York (NY): Schattauer Verlag, Stuttgart; 1987.

45. Statistics Sweden. Labour force surveys. Stockholm: Statistics Sweden; 1999.

46. Landsbergis PA, Cahill J, Schnall P. The impact of lean production and related new systems of work organization on worker health. J Occup Health Psychol 1999;4(2):108-30.

47. Marklund S, editor. Worklife and health in Sweden 2000. Stockholm: Swedish Work Environment Authority and Arbetslivsinstitutet [National Institute for Working Life]; 2001.

48. Kilbom $\AA$, Messing K, Bildt Thorbjörnsson C, editors. Women's health at work. Stockholm: Arbetslivsinstitutet (National Institute for Working Life); 1998.

49. Härenstam A, Bodin L, Karlqvist L, Nise G, Schéele P, the MOA Research Group. Patterns of working and living conditions: a holistic, multivariate approach to occupational-health studies. Work Stress 2003;17:1.

50. Ilmarinen J, Louhevaara V, Korhonen O, Nygård C-H, Hakola $\mathrm{T}$, Suvanto $\mathrm{S}$. Changes in maximal cardiorespiratory capacity among aging municipal employees. Scand J Work Environ Health 1991;17 Suppl 1:99-109.

51. Östlin P. Negative health selection into physically light occupations. J Epidemiol Community Health 1988;42:152-6.

Received for publication: 17 July 2002 


\section{Appendix 1}

Block 1. Psychosocial exposures at work as measured by observation and questionnaire methods among the cases (25 men and 21 women) and noncases (69 men and 73 women). A higher index or percentage of worktime indicates worse situations in six variables and better in four variables. The gray area indicates variables included in the logistic regression models.

\begin{tabular}{|c|c|c|c|c|c|c|c|c|c|c|c|c|c|c|c|c|c|c|c|c|}
\hline \multirow[t]{3}{*}{ Gender } & \multicolumn{12}{|c|}{ Expert assessment } & \multicolumn{8}{|c|}{ Self-reports } \\
\hline & \multicolumn{2}{|c|}{$\begin{array}{l}\text { Influence } \\
\text { (index 0-3) }\end{array}$} & \multicolumn{2}{|c|}{$\begin{array}{l}\text { Obstacles } \\
\text { or job per- } \\
\text { formance } \\
\text { (index 3-9) }\end{array}$} & \multicolumn{2}{|c|}{$\begin{array}{l}\text { Routine } \\
\text { work } \\
(\% a)\end{array}$} & \multicolumn{2}{|c|}{$\begin{array}{l}\text { Creative } \\
\text { work } \\
\left(\%^{a}\right)\end{array}$} & \multicolumn{2}{|c|}{$\begin{array}{l}\text { Time } \\
\text { pressure } \\
\left(\%{ }^{a}\right)\end{array}$} & \multicolumn{2}{|c|}{$\begin{array}{l}\text { Time-bound } \\
\text { work } \\
\left(\%{ }^{a}\right)\end{array}$} & \multicolumn{2}{|c|}{$\begin{array}{l}\text { Job de- } \\
\text { mands } \\
\text { (index 6-21) }\end{array}$} & \multicolumn{2}{|c|}{$\begin{array}{l}\text { Control } \\
\text { (index } \\
10-24 \text { ) }\end{array}$} & \multicolumn{2}{|c|}{$\begin{array}{l}\text { Skill dis- } \\
\text { cretion } \\
\text { (index 8-20) }\end{array}$} & \multicolumn{2}{|c|}{$\begin{array}{l}\text { Social } \\
\text { support } \\
\text { (index 3-10 }\end{array}$} \\
\hline & Mear & $\mathrm{SD}$ & Mean & $\mathrm{SD}$ & Mear & SD & Mean & SD & Mear & $\mathrm{SD}$ & Mean & $\mathrm{SD}$ & Mean & SD & Mean & SD & Mean & $\mathrm{SD}$ & Mean & SD \\
\hline \multicolumn{21}{|l|}{ Men } \\
\hline Cases & 1.4 & 0.8 & 4.3 & 1.5 & 61 & $28^{b}$ & 4.8 & 9.2 & 28 & 39 & 12 & $28^{b}$ & 13 & 3.0 & 17 & 3.4 & 11.1 & $2.1^{b}$ & 5.3 & 1.7 \\
\hline Noncases & 1.5 & 1.0 & 4.0 & 1.5 & 29 & 23 & 7.8 & 8.1 & 28 & 40 & 30 & 38 & 13 & 2.9 & 18 & 3.3 & 12.3 & 2.1 & 5.3 & 1.7 \\
\hline \multicolumn{21}{|l|}{ Women } \\
\hline Cases & 0.9 & $0.4^{b}$ & 5.0 & $2.1^{b}$ & 44 & $31^{b}$ & 4.1 & $3.8^{b}$ & o 40 & 47 & 46 & $46^{b}$ & 14 & 3.1 & 17 & 2.4 & 10.8 & $1.5^{b}$ & 5.7 & 2.0 \\
\hline Noncases & 1.5 & 0.9 & 4.1 & 1.6 & 25 & 22 & 7.3 & 7.1 & 32 & 41 & 16 & 30 & 13 & 3.1 & 18 & 3.5 & 11.8 & 2.1 & 5.0 & 1.6 \\
\hline
\end{tabular}

a Percentage of worktime.

b Significant differences between the cases and noncases $(P<0.05)$.

\section{Appendix 2}

Block 2. Chemical-physical exposures at work as measured by expert evaluation, technical measurement, or questionnaire methods among the cases ( 25 men and 21 women) and noncases (69 men and 73 women). A higher index indicates worse situations. The gray area indicates variables included in the logistic regression models.

\begin{tabular}{|c|c|c|c|c|c|c|}
\hline \multirow[t]{2}{*}{ Gender } & \multicolumn{2}{|c|}{ Physical environment ${ }^{\text {a }}$ (index 6-17) } & \multicolumn{2}{|c|}{ Measured noise level ${ }^{b}[\mathrm{~dB}(\mathrm{~A})]$} & \multicolumn{2}{|c|}{ Chemical exposures ${ }^{\circ}$ (index 10-35) } \\
\hline & Mean & SD & Mean & SD & Mean & SD \\
\hline \multicolumn{7}{|l|}{ Men } \\
\hline Cases & 9.8 & $3.7^{d}$ & 81 & $6.4^{d}$ & 16.6 & $6.7^{d}$ \\
\hline Noncases & 7.6 & 2.0 & 77 & 5.5 & 12.8 & 3.3 \\
\hline \multicolumn{7}{|l|}{ Women } \\
\hline Cases & 8.1 & $2.5^{d}$ & 78 & $5.0^{d}$ & 14.9 & $5.9^{d}$ \\
\hline Noncases & 7.2 & 1.7 & 75 & 3.8 & 12.5 & 3.0 \\
\hline
\end{tabular}

a Expert assessment.

b Body attached measurement.

- Questionnaire.

d Significant differences between the cases and noncases $(P<0.05)$.

\section{Appendix 3}

Block 3. Workhours and schedules of the cases ( 25 men and 21 women) and noncases ( 69 men and 73 women). The gray area indicates variables included in the logistic regression models.

\begin{tabular}{|c|c|c|c|c|c|c|c|c|c|}
\hline \multirow[t]{2}{*}{ Gender } & \multirow[t]{2}{*}{$\begin{array}{c}\text { Atypical or irregular } \\
\text { work schedule } \\
(\%)\end{array}$} & \multicolumn{2}{|c|}{ Ordinary work ${ }^{a}$} & \multicolumn{2}{|c|}{$\begin{array}{c}\text { Extra jobs } \\
\text { (hours/week) }\end{array}$} & \multicolumn{2}{|c|}{$\begin{array}{c}\text { Commuting } \\
\text { (hours/week) }\end{array}$} & \multicolumn{2}{|c|}{$\begin{array}{c}\text { Total time } \\
\text { in the work sphere } \\
\text { (hours/week) }\end{array}$} \\
\hline & & Mean & Range & Mean & Range & Mean & Range & Mean & Range \\
\hline \multicolumn{10}{|l|}{ Men } \\
\hline Cases & 38 & 41 & $37-50$ & $9.6^{b}$ & 4-20 & 5 & $0-10^{c}$ & 49 & $39-62$ \\
\hline Noncases & 36 & 42 & $15-70$ & $9.7^{d}$ & $3-25$ & 3 & $0-12$ & 46 & $17-82$ \\
\hline \multicolumn{10}{|l|}{ Women } \\
\hline Cases & $47^{c}$ & 38 & $17-49$ & - & .. & 4 & $0-10$ & 42 & $21-55$ \\
\hline Noncases & 34 & 40 & 17-75 & $7.3^{e}$ & $2-18$ & 4 & $0-10$ & 45 & $19-64$ \\
\hline
\end{tabular}

a Including paid breaks and over-time work.

${ }^{b} \mathrm{~N}=7$.

c Significant differences between the cases and noncases $(P<0.05)$.

${ }^{\mathrm{b}} \mathrm{N}=8$.

b $\mathrm{N}=7$. 


\section{Appendix 4}

Block 4. Activities outside paid work as determined by the interview method among the cases ( 25 men and 21 women) and noncases (69 men and 73 women). The gray area indicates variables included in the logistic regression models.

\begin{tabular}{|c|c|c|c|c|c|c|c|c|}
\hline \multirow[t]{2}{*}{ Gender } & \multicolumn{2}{|c|}{$\begin{array}{l}\text { Home and household work } \\
\text { (hours/week) }\end{array}$} & \multicolumn{2}{|c|}{$\begin{array}{l}\text { Ather compulsory tasks } \\
\text { (hours/week) }\end{array}$} & \multicolumn{2}{|c|}{$\begin{array}{l}\text { Time for own recreation } \\
\text { (hours/week) }\end{array}$} & \multicolumn{2}{|c|}{$\begin{array}{l}\text { Exercises (included in own recreation) } \\
\text { (hours/week) }\end{array}$} \\
\hline & Mean & Range & Mean & Range & Mean & Range & Mean & Range \\
\hline \multicolumn{9}{|l|}{ Men } \\
\hline Cases & 12 & $1-33$ & 1 & $0-5$ & 52 & $32-70$ & 3 & $0-11$ \\
\hline Noncases & 14 & $1-43$ & 1 & $0-14$ & 51 & $13-85$ & 5 & $0-26$ \\
\hline \multicolumn{9}{|l|}{ Women } \\
\hline Cases & 19 & $5-54$ & - & .. & 51 & $16-78$ & 4 & $0-14$ \\
\hline Noncases & 19 & $4-54$ & 1 & $0-12$ & 48 & $10-78$ & 4 & $0-16$ \\
\hline
\end{tabular}

\section{Appendix 5}

Block 4. Ergonomic-physical exposures during leisure-time activities as determined by the interview method and by technical measurements among the cases ( 25 men and 21 women) and noncases ( 69 men and 73 women). The gray area indicates the variable included in the logistic regression models.

\begin{tabular}{|c|c|c|c|c|c|c|c|c|c|c|c|c|}
\hline \multirow[t]{3}{*}{ Gender } & \multicolumn{6}{|c|}{ Leisure-time activities } & \multicolumn{6}{|c|}{ Outside paid work per workday } \\
\hline & \multicolumn{2}{|c|}{$\begin{array}{l}\text { TWA-MET a } \\
\text { outside paid work/ } \\
\text { workday }\end{array}$} & \multicolumn{2}{|c|}{$\begin{array}{l}\text { TWA-MET a on } \\
\text { a nonworkday }\end{array}$} & \multicolumn{2}{|c|}{$\begin{array}{l}\text { Sitting during leisure } \\
\text { time (hours/week) }\end{array}$} & \multicolumn{2}{|c|}{$\begin{array}{l}\text { Walking distance } \\
\text { (meter/hour) }\end{array}$} & \multicolumn{2}{|c|}{$\begin{array}{l}\text { Heart rate range } \\
(\%)\end{array}$} & \multicolumn{2}{|c|}{$\begin{array}{l}\text { Sitting }{ }^{b} \\
(\%)\end{array}$} \\
\hline & Mean & SD & Mean & $\mathrm{SD}$ & Mean & SD & Mean & $\mathrm{SD}$ & Mean & SD & Mean & SD \\
\hline \multicolumn{13}{|l|}{ Men } \\
\hline Cases & 2.1 & 0.5 & 2.0 & 0.4 & 39 & 12 & 433 & 304 & $26^{c}$ & 9.3 & 55 & 17 \\
\hline Noncases & 2.1 & 0.5 & 2.1 & 0.4 & 37 & 12 & 436 & 258 & 18 & 5.6 & 51 & 17 \\
\hline \multicolumn{13}{|l|}{ Women } \\
\hline Cases & 2.1 & 0.3 & 2.0 & 0.3 & 6 & 12 & 562 & 317 & 19 & 4.8 & 51 & 14 \\
\hline Non-ases & 2.1 & 0.4 & 2.2 & 0.3 & 35 & 11 & 437 & 282 & 18 & 5.0 & 49 & 15 \\
\hline
\end{tabular}

a Time-weighted average of the metabolic equivalent.

${ }^{\mathrm{b}}$ Posimeter.

c Significant differences between the cases and noncases $(P<0.05)$.

\section{Appendix 6}

Block 4. Domestic work and experienced physical exertion during leisure-time activities as measured by questionnaire methods among the cases ( 25 men and 21 women) and noncases (69 men and 73 women). A higher index indicates more straining domestic work. The gray area indicates the variable included in the logistic regression models.

\begin{tabular}{|c|c|c|c|c|}
\hline \multirow[t]{3}{*}{ Gender } & \multicolumn{4}{|c|}{ Domestic work } \\
\hline & \multicolumn{2}{|c|}{ Index a } & \multicolumn{2}{|c|}{ Physical exertion } \\
\hline & Mean & $\mathrm{SD}$ & Mean & $\mathrm{SD}$ \\
\hline \multicolumn{5}{|l|}{ Men } \\
\hline Cases & 4.1 & 1.1 & 12 & 2.1 \\
\hline Noncases & 4.4 & 1.2 & 12 & 2.9 \\
\hline \multicolumn{5}{|l|}{ Women } \\
\hline Cases & 4.9 & 1.3 & 12 & 2.7 \\
\hline Noncases & 4.6 & 1.3 & 12 & 2.6 \\
\hline
\end{tabular}

a Index 3-11, based on three questions of the Public Health Questionnaire. 


\section{Appendix 7}

Block 5. Life-style factors of the cases ( 25 men and 21 women) and noncases ( 69 men and 73 women) according ot their self-report. The gray area indicates variables included in the logistic regression models.

\begin{tabular}{|c|c|c|c|c|c|c|c|}
\hline \multirow[t]{3}{*}{ Gender } & \multicolumn{7}{|c|}{ Self-reports } \\
\hline & \multirow{2}{*}{$\begin{array}{c}\text { Smokers } \\
\text { (daily) } \\
(\%)\end{array}$} & \multirow{2}{*}{$\begin{array}{l}\text { Above average alco- } \\
\text { hol consumption a } \\
(\%)\end{array}$} & \multirow{2}{*}{$\begin{array}{l}\text { Heavy drinking at least } \\
\text { once a week b } \\
(\%)\end{array}$} & \multicolumn{2}{|c|}{ Body mass index } & \multirow{2}{*}{$\begin{array}{c}\text { Overweight c } \\
(\%)\end{array}$} & \multirow{2}{*}{$\begin{array}{c}\text { No or little regular } \\
\text { physical } \\
\text { exercise }^{d}\end{array}$} \\
\hline & & & & Mean & $\mathrm{SD}$ & & \\
\hline \multicolumn{8}{|l|}{ Men } \\
\hline Cases & 21 & $43^{e}$ & $17^{e}$ & 26 & $20-33$ & $68^{e}$ & 44 \\
\hline Noncases & 17 & 15 & 4 & 25 & $20-35$ & 42 & 36 \\
\hline \multicolumn{8}{|l|}{ Women } \\
\hline Cases & 10 & $0^{e}$ & 0 & 27 & $18-42^{e}$ & 54 & $62^{e}$ \\
\hline Noncases & 21 & 10 & 1 & 24 & $17-32$ & 37 & 25 \\
\hline
\end{tabular}

a High-alcohol beer at least once a week.

b Above average.

${ }^{c}$ As defined by the World Health Organization.

d Less than 120 minutes per week.

c Significant differences between the cases and noncases $(P<0.05)$. 